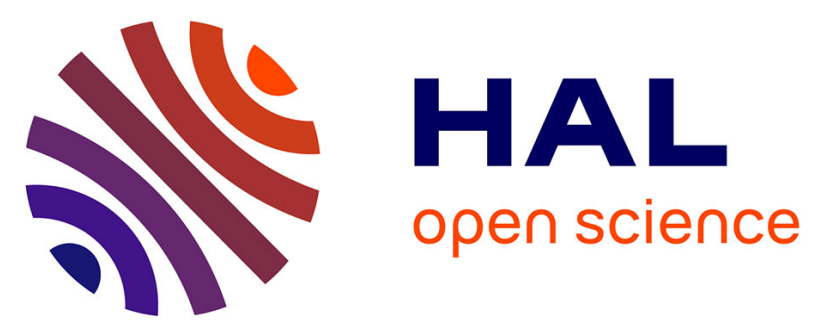

\title{
Aircraft noise exposure and subjective sleep quality: the results of the DEBATS study in France
}

\author{
Ali-Mohamed Nassur, Marie Lefevre, Bernard Laumon, Damien Léger, Anne
} Sophie Evrard

\section{- To cite this version:}

Ali-Mohamed Nassur, Marie Lefevre, Bernard Laumon, Damien Léger, Anne Sophie Evrard. Aircraft noise exposure and subjective sleep quality: the results of the DEBATS study in France. Behavioral Sleep Medicine, In press, 10.1080/15402002.2017.1409224 . hal-01704804

\section{HAL Id: hal-01704804 \\ https://hal.science/hal-01704804}

Submitted on 8 Feb 2018

HAL is a multi-disciplinary open access archive for the deposit and dissemination of scientific research documents, whether they are published or not. The documents may come from teaching and research institutions in France or abroad, or from public or private research centers.
L'archive ouverte pluridisciplinaire HAL, est destinée au dépôt et à la diffusion de documents scientifiques de niveau recherche, publiés ou non, émanant des établissements d'enseignement et de recherche français ou étrangers, des laboratoires publics ou privés. 
Title: Aircraft noise exposure and subjective sleep quality: the results of the DEBATS study in France

\section{Authors:}

Ali-Mohamed NASSUR ${ }^{1}$, Marie LEFÈVRE ${ }^{1}$, Bernard LAUMON ${ }^{2}$, Damien LÉGER ${ }^{3}$, AnneSophie EVRARD ${ }^{1}$

\section{Author affiliations:}

${ }^{1}$ Univ Lyon, Université Claude Bernard Lyon1, IFSTTAR, UMRESTTE, UMR T_9405, Bron, France

${ }^{2}$ IFSTTAR, Transport, Health and Safety Department, Bron, France

${ }^{3}$ Université Paris Descartes, Sorbonne Paris Cité, APHP, Hôtel-Dieu de Paris, Centre du Sommeil et de la Vigilance et EA 7330 VIFASOM, Paris, France 


\section{Correspondence to:}

Anne-Sophie Evrard

IFSTTAR

Cité des Mobilités, 25 avenue François Mitterrand, F-69675, Bron, France

Tel.: 0033472142463

Fax: 0033472376837

anne-sophie.evrard@ifsttar.fr

Word count: 3,811

\section{Contributors:}

Anne-Sophie Evrard (ASE) and Bernard Laumon (BL) conceived of and designed the study. ASE and Marie Lefèvre (ML) conducted the study. ML was involved in data extraction and preparation and Ali-Mohamed Nassur (AMN) performed the statistical analyses, supervised by ASE and BL. The analyses were interpreted by AMN and ASE with BL and Damien Léger (DL). AMN and ASE drafted the initial report. All coauthors revised the report and approved the final version. ASE is responsible for the overall content as the guarantor of this paper. 


\section{Abstract}

Background: Exposure to aircraft noise has been shown to have adverse effects on health, particularly on sleep. Exposure to nighttime aircraft noise clearly affects sleep architecture, as well as subjective sleep quality.

Objectives: This study aimed to investigate the relationship between aircraft noise exposure and subjective sleep quality in the population living near airports in France.

Methods: A total of 1,244 individuals older than 18 and living near three French airports (ParisCharles de Gaulle, Lyon-Saint-Exupéry and Toulouse-Blagnac) were randomly selected to participate in the study. Information on sleep as well as health, socioeconomic and lifestyle factors was collected by means of a face-to-face questionnaire performed at their place of residence by an interviewer. For each participant, aircraft noise exposure was estimated at home using noise maps. Logistic regression models were used with adjustment for potential confounders.

Results: Aircraft noise exposure was significantly associated with a short total sleep time (TST) ( $\leq 6 \mathrm{~h}$ ) and with the feeling of tiredness while awakening in the morning. An increase of 10 $\mathrm{dB}(\mathrm{A})$ in aircraft noise level at night was associated with an OR of 1.63 (95\%CI: 1.15-2.32) for a short TST and an OR of 1.23 (95\%CI: 1.00-1.54) for the feeling of tiredness while awakening in the morning.

Conclusions: These findings contribute to the overall evidence suggesting that aircraft noise exposure at nighttime may decrease the subjective amount and quality of sleep.

Key words: Epidemiology; aircraft noise exposure; sleep quality 


\section{INTRODUCTION}

Sleep is essential for physical and mental well-being. Sleep has a restorative function on physical and mental fatigue, helps to maintain metabolism and is one of the most important factors responsible for the maintenance of a healthy organism, thus representing a homeostatic need required for life. Sleep satisfaction is increasingly disturbed by external aggressions, voluntarily or not, among which noise is a major cause.

Transportation noise is a major source of environmental noise pollution, and it represents a major public health issue. According to the World Health Organization (WHO), transportation noise is estimated to cause at least one million healthy life years lost every year in Western Europe, and sleep disorders are the most serious consequence with more than 900 thousand years of life lost every year, mostly related to road traffic noise (WHO, 2011). In addition, poor sleep, especially short sleep ( $<6$ hours), has been found to be associated with many major comorbidities, e.g., obesity, hypertension, type 2 diabetes, cardiovascular disease, depression, and increased risk of mortality (Cappuccio et al., 2008; Cappuccio, D’Elia, Strazzullo, \& Miller, 2010; Gangwisch et al., 2006; Grandner, Jackson, Pak, \& Gehrman, 2012; Jones \& Rhodes, 2013; Mallon, Broman, \& Hetta, 2000; Phillips \& Mannino, 2007; Tasali, Leproult, Ehrmann, \& Van Cauter, 2008; Vgontzas et al., 2010).

Aircraft noise in particular is perceived as a major environmental stressor in the vicinity of airports, and the impact of the long-term exposure to aircraft noise on health is of growing concern (Lekaviciute Gadal, Kephalopoulos, Stansfeld, \& Clark, 2013) because of a steady rise in flights and a population increasingly dissatisfied with this noise (Babisch et al., 2009).

Several studies have already been conducted on the effects of aircraft noise on sleep; however, most of these studies are cross-sectional, with few prospective studies (Michaud, Fidell, Pearsons, Campbell, \& Keith, 2007; Perron, Tetreault, King, Plante, \& Smargiassi, 2012). In 
both laboratory and field studies, exposure to aircraft noise has been shown to disrupt sleep (Basner, Griefahn, \& Berg, 2010; Passchier-Vermeer, Vos, Steenbekkers, van der Ploeg, \& Groothuis-Oudshoorn, 2002; Perron et al., 2012). Exposure to nighttime aircraft noise leads to an increased frequency of awakening, increased motility, decreased slow wave sleep, changes in sleep structure, use of sleep drugs or sedatives, and a poor self-reported quality of sleep (Perron et al., 2012). An increased time for falling asleep, a decreased total sleep duration and an increased feeling of being tired while awakening in the morning have also been reported (Passchier-Vermeer et al., 2002; Perron et al., 2012).

In France, however, the effects of aircraft noise exposure on sleep quality in the population living near airports have never been prospectively evaluated. The objective of the DEBATS research program (Discussion on the health effects of aircraft noise) is to characterize and quantify the effects of long-term aircraft noise exposure on health, especially on sleep disturbance, among the French population living in the vicinity of airports. The study includes a longitudinal field study that aims to follow-up approximately 1,200 French airport residents over four years. The participants were interviewed in 2013 and in 2015 and were again interviewed in 2017.

Based on data collected in 2013 when the participants were included in the study, the present paper more specifically addresses the issue of an association between aircraft noise exposure and subjective sleep quality. 


\section{METHODS}

\section{Study population}

The DEBATS study population included people older than 18 years of age at the time of the first interview, living near one of the following three French international airports: ParisCharles de Gaulle, Lyon Saint-Exupéry, and Toulouse-Blagnac. In total, 1,244 participants (549 men and 695 women) were initially included in the main study (Evrard, Lefèvre, Champelovier, Lambert, \& Laumon, 2017). For their inclusion in the study in 2013, these participants filled out a questionnaire during a face-to-face interview at their place of residence. Information was collected by an interviewer on demographic variables, socioeconomic status, lifestyle factors, including smoking, alcohol consumption, and physical activity, personal medical history in terms of sleep disturbances, cardiovascular diseases, anxiety, depressive disorders, medication use, and finally annoyance due to noise exposure. Blood pressure and anthropometric measurements (weight, height and waist circumference) were also recorded, and saliva samples were also taken to determine cortisol levels. This procedure is described in detail elsewhere (Evrard et al., 2017; Lefèvre et al., 2017).

\section{Aircraft noise exposure assessment}

The French Civil Aviation Authority for Toulouse-Blagnac and Lyon Saint-Exupéry airports and Paris Airports produce outdoor noise exposure maps with the "Integrated Noise Model” (INM) (He et al., 2007). The INM is an internationally well-established computer model that evaluates aircraft noise impacts in the vicinity of airports and outputs noise contours for an area (Figure 1). Based on aircraft performance data, noise emissions and propagation were modeled by the INM using input data such as estimated air traffic, applicable air traffic control procedures (including flight track dispersion), infrastructure in use at the airport, topography and weather conditions. The values of different noise indicators were then estimated at different 
grid points. Aircraft noise exposure was assessed in 1-dBA intervals for each participant with a linkage between the noise contours and their home address using a geographic information system (GIS) technique. The following four noise indicators using three different periods of the day were derived and used in the statistical analyses: the average sound level for $24 \mathrm{hr}$ ( $\mathrm{L}_{\text {Aeq,24hr }}$, the average during the day and the evening (LAeq,6hr-22hr), the average during the night (Lnight), and finally the weighted average of sound levels $\left(\mathrm{L}_{\mathrm{den}}\right)$ from day (06:00 to 18:00), evening (18:00 to 22:00) and night (22:00 to 06:00), where evening and night sound pressure levels receive a $5 \mathrm{~dB}(\mathrm{~A})$ and a $10 \mathrm{~dB}(\mathrm{~A})$ penalty respectively to reflect the extra sensitivity to noise during the evening and the night. Lden is the "general purpose" indicator defined in EU-directive 2002/49 relating to the assessment and management of environmental noise. The $\mathrm{Lden}$ indicator was used to select the participants (Table 1).

\section{Sleep assessment}

Sleep was assessed subjectively based on the following two items:

- “At what time do you usually go to bed to sleep on a weeknight (off light)?”

- “At what time do you usually get up on a weeknight?”

Total sleep time (TST) was calculated as the difference between the time of going to sleep and the time of getting up. TST was then categorized into two classes, "short TST" ( $\leq 6$ hours) versus "normal and long TST" (> 6 hours). Indeed, in adults, sleeping less than 6 hours during working days is usually considered as the "cut off" for "short TST" with potential comorbidities (Cappuccio et al., 2010; Kurina et al., 2013).

In the questionnaire, the participants also characterized how they felt while awakening after a usual night sleep as follows: well rested, rather rested, rather tired or very tired. This variable was then categorized into the following two classes: well/rather rested versus rather/very tired. 


\section{Confounding factors}

The following several factors that are known to affect subjective sleep quality were obtained from the questionnaire and were included in the multivariate regression model (Beck, Richard, \& Léger, 2013; Leger, Beck, Richard, Sauvet, \& Faraut, 2014; Marks \& Griefahn, 2007; Ohayon, 2002) (M1 model): age (continuous), gender (dichotomous), education (three categories: <French high school certificate/=French high school certificate/>French high school certificate), marital status (four categories: single/married/widowed/divorced), smoking habits (four categories: non/ex/occasional/daily smoker), alcohol consumption (four categories: no/light/moderate/heavy drinker), physical activity (no/yes), self-reported health (two categories: fair or poor /good or excellent), body mass index (BMI, body weight divided by height squared, three categories: obesity/ overweight/underweight or normal weight), selfreported anxiety (two categories: extremely or a lot/moderately, slightly or not at all), selfreported depression (two categories: extremely or a lot/moderately, slightly or not at all), and sensitivity to noise (three categories: less sensitive than/as sensitive as/more sensitive than people around you). Household monthly income (three categories: < 2300; 2300-4000; >=4000 euro) was also introduced in the M1 model, instead of education level.

Other potential confounders with a p-value of 0.30 or less in univariate analyses were entered in the multivariate model (M1 model) as follows: work schedule (four categories: always during the night/always during the day/shift work/not applicable), physical tiredness (two categories: extremely or a lot/moderately, slightly or not at all), nervous tiredness (two categories: extremely or a lot/moderately, slightly or not at all), cardiovascular disease (no/yes), and hypertension (no/yes).

As annoyance may be an intermediate step in the causal chain between aircraft noise exposure and subjective sleep quality, annoyance from aircraft noise exposure (two categories: extremely 
or a lot / moderately, slightly or not at all annoyed) was then added in the fully adjusted regression model (M2 model).

The analyses were also restricted to the 991 participants who resided at their address for at least 5 years.

\section{Statistical analyses}

The age-standardized prevalence for a short TST and for the feeling of tiredness while awakening was calculated for each gender and both genders together using as the standard population the age structure of the French population in 2012 derived from the French national census.

Logistic regression models with short TST or the feeling of tiredness while awakening as the outcome variable and aircraft noise exposure and confounders as covariates were used to assess the associations between aircraft noise and subjective sleep quality. Linear regression models with sleep duration as the outcome variable were also used to estimate the association between aircraft noise exposure and sleep duration. These models were adjusted on the same confounders as those included in the logistic regression models. The results and their discussion are presented in a supplementary Table.

The linearity of the relationship between the dependent variable and aircraft noise exposure was tested using generalized additive models, including a smooth cubic function with linear and quadratic terms for aircraft noise exposure (Wood, 2006). As the quadratic term was not significant in these models, associations with the continuous exposure variable per $10 \mathrm{~dB}(\mathrm{~A})$ increase were finally estimated and presented in the present paper.

Statistical analyses were conducted using SAS version 9.4 (SAS Software [program] 9.4 version. USA: Cary North Carolina, USA 2014). 


\section{RESULTS}

The age-standardized prevalence (to the French population) of a short TST ( $\leq 6 \mathrm{hr}$ ) was $11 \%$ in men and 7\% in women. The sex- and age-standardized prevalence of a short TST was $9 \%$. The percentage of participants with a short TST was significantly higher for aircraft noise levels higher than $60 \mathrm{~dB}(\mathrm{~A})$ (Lden) compared to those lower than $55 \mathrm{~dB}(\mathrm{~A})\left(\mathrm{Lden}_{\mathrm{de}}\right.$ p=0,05) (Table 1).

The age-standardized prevalence (to the French population) of the feeling of tiredness while awakening in the morning after a night's sleep was $22 \%$ in men and $35 \%$ in women. The sexand age-standardized prevalence of the feeling of tiredness while awakening was $30 \%$. The percentage of participants feeling rather/very tired while awakening was not significantly higher for those with aircraft noise levels higher than $60 \mathrm{~dB}(\mathrm{~A})\left(\mathrm{L}_{\mathrm{den}}\right)$ compared to those with aircraft noise exposure lower than $55 \mathrm{~dB}(\mathrm{~A})\left(\mathrm{Lden}_{\mathrm{de}} \mathrm{p}=0.50\right)$ (Table 1).

Table 2 shows the odds-ratios (OR) and their 95\% CIs for a short TST and the feeling of tiredness while awakening in relation to the major a priori confounders. Men (compared to women), single people (compared to married people), daily smokers (compared to nonsmokers), anxious people, shift workers and people always working during the night (compared to those always working during the day) had a higher probability of a short TST ( $\leq 6 \mathrm{hr})$. Annoyance was not significantly associated with a short TST. Regarding the feeling of tiredness while awakening, women (compared to men), participants with a degree $<$ French high school certificate (compared to > French high school certificate), young people, participants who reported a fair or a poor perceived health, participants who reported to be more sensitive to noise than people around them (compared to those who reported to be as sensitive to noise as people around them), anxious people, and those who reported to be physically or nervously tired were more likely to be rather or very tired while awakening in the morning. The feeling of tiredness while awakening was positively and significantly associated with annoyance due 
to aircraft noise. Household monthly income was neither associated with a short TST nor with the feeling of tiredness while awakening.

The ORs and their 95\% CIs for a short TST or the feeling of tiredness while awakening in relation to aircraft noise exposure are presented in Table 3. Analyses were performed separately

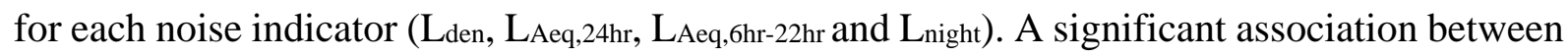
a short TST or the feeling of tiredness while awakening and aircraft noise exposure was found regardless of the noise indicator, when annoyance was not included in the models; Participants with higher noise levels had a higher probability of a short TST and felt rather or very tired more often while awakening compared to those with lower noise levels. The ORs were very similar for all noise indicators. A $10 \mathrm{~dB}(\mathrm{~A})$ increase in aircraft noise level at night was associated with an OR of 1.63 (95\%CI: 1.15-2.32) for a short TST and 1.23 (95\% CI: 1.001.54) for the feeling of tiredness while awakening. When annoyance was included in the models, the results remained similar for a short TST. In contrast, the association between aircraft noise exposure and the feeling of tiredness while awakening was no longer significant, regardless of the noise indicator. The results of the M1 and M2 models remained similar when household monthly income was introduced in the models instead of education level.

Table 4 displays the ORs and their 95\% CIs for a short TST or the feeling of tiredness while awakening in relation to aircraft noise exposure for the 991 participants who had resided at their address for at least 5 years. The association remained significant for a short TST but became non-significant for the feeling of tiredness while awakening in the morning. 


\section{DISCUSSION}

The sex- and age-standardized (to the French population) prevalence of a short TST ( $\leq 6 \mathrm{hr}$ ) estimated in the DEBATS study was very similar to the one observed in the INPES (National Institute for Prevention and Health Education) study in subjects between 15 and 85 years of age in France in 2010. In the INPES study, the prevalence of short sleep ( $<5 \mathrm{hr}$ ) was 8\% (Leger et al., 2014). Sleeping less than 6 hours is usually considered the "cut off”, for "a short sleep duration"' with potential comorbidities (Cappuccio et al., 2010; Kurina et al., 2013). The percentage of the participants reported to be rather or very tired while awakening in the morning in the DEBATS study (30\% of the participants older than 18 years of age) was also very similar to the one found in the French Health, Health Care and Insurance Survey where $34 \%$ of the French population aged 16 and above reported tiredness on awakening (Gourier-Fréry, ChanChee, \& Léger, 2012).

The increasing air transportation traffic in all parts of the world has led authorities to seek measures to better control the potential impact of aircraft noise on health. Indeed, at night, the urban global level of noise is usually lower than daytime, but the impact of night flights is considered the most disturbing by near-airport populations. Moreover, as underlined by the WHO recommendations on "Noise on health", airport noise may alter the ability of more vulnerable people to rest at night. Many studies have already been conducted on the effects of aircraft noise on sleep, and exposure to aircraft noise has been shown to disrupt sleep with an increased frequency of awakening, increased motility, decreased slow wave sleep, changes in sleep structure, use of sleep drugs or sedatives, a poor self-reported quality of sleep, an increased time for falling asleep, a decreased total sleep duration and an increased feeling of being tired while awakening in the morning (Jones \& Rhodes, 2013; Michaud et al., 2007; Perron et al., 2012). However, the number of these studies investigating sleep duration is still limited and their results remain unclear (Perron et al., 2012). A few studies have evaluated the 
relationship between aircraft noise and sleep duration, and most of them have been performed in a laboratory. Some of these studies showed a significantly decreased sleep duration (Kim et al., 2014) or not (Basner, Buess, Mueller, Plath, \& Samel, 2004; Basner \& Samel, 2004) when aircraft noise exposure increased, whereas others did not show any association (Basner, Glatz, Griefahn, Penzel, \& Samel, 2008; Griefahn, Marks, \& Robens, 2006).

The present study confirms the findings by Kim et al who found that the sleep duration of 1,082 residents near a military airfield was lower in the highly exposed group, followed by the lowexposure group and finally the control group (Kim et al., 2014). Indeed, as suggested by Muzet (Muzet, 2007), TST can be reduced by an increased sleep latency, prolonged nocturnal awakenings or by an early morning awakening (Muzet, 2007). It is well established that exposure to aircraft noise leads to an increased frequency of awakenings and an increased time to fall asleep.

Controlling for several factors that are known to affect subjective sleep quality and for other potential confounders did not change the significant associations. In this study, the assessment of extensive covariate data made it possible to evaluate a large number of possible confounding factors and ensure the stability of the results.

However, uncontrolled or residual confounding, exposure misclassification, and selection bias all need to be considered. As the association between aircraft noise exposure and a short TST remained similar when annoyance from aircraft noise exposure was included in the models, the present study does not support the hypothesis that the effects of noise exposure on sleep duration are mediated through annoyance. This could either indicate that the evidenced association reflects residual confounding because the selected variable (annoyance from aircraft noise exposure) does not effectively characterize annoyance or that the shorter sleep duration observed in this study is directly connected to aircraft noise exposure. 
The results of the present study also confirm those found in the literature, namely, an association between aircraft noise exposure and the feeling of tiredness while awakening in the morning (Griefahn et al., 2006; Jones \& Rhodes, 2013). However, the association between aircraft noise exposure and the feeling of tiredness while awakening was no longer significant when annoyance from aircraft noise exposure was included in the models. Therefore, it is very likely that the effects of noise exposure on the feeling of tiredness while awakening are mediated through annoyance. Frei and al. found that the association between self-reported sleep quality and noise was mediated through noise annoyance, whereas objective sleep quality was independent of perceived noise annoyance (Frei, Mohler, \& Roosli, 2014). The present study seems to confirm these findings if TST is considered the most objective variable characterizing self-reported sleep quality and the feeling of tiredness while awakening is considered subjective.

When the analyses were restricted to the 991 participants who resided at their address for at least 5 years, the association remained significant for a short TST but became non-significant for the feeling of tiredness while awakening in the morning. These results support the hypothesis of a sleep habituation to transportation noise for subjective sleep quality and not for objective sleep quality (Kawada et al., 2001; Kuroiwa et al., 2002; Muzet, 2007).

The present study had specific strength in the evaluation of noise exposure. Indeed, aircraft noise exposure was estimated for each participant using modeled noise levels produced by the French Civil Aviation Authority using the INM software. These modeled noise levels were validated by comparison with measurements from permanent stations (Aéroports de Paris, 2007) or from specific campaigns (Foret, Bruyere, \& Yombo, 2005). Most of the differences were between 0.5 and $1.5 \mathrm{~dB}(\mathrm{~A})$ in terms of Lden, thus showing the validity of the modeled noise levels. 
Moreover, a short TST and a feeling of tiredness while awakening were significantly associated with day-evening-night, day- and night-time exposures to aircraft noise. In the literature, different indicators have been used to describe the effects of aircraft noise on sleep quality (Finegold, 2010). Most studies have considered nighttime (Lnight) noise exposure (Jones \& Rhodes, 2013; Miedema \& Vos, 2007), but some studies have shown that exposure to daytime noise can disrupt sleep (Fruhstorfer, Fruhstorfer, \& Grass, 1984) and reduce sleep duration (Blois, Debilly, \& Mouret, 1980). In the present study, day-evening-night, day- and night-time exposures to aircraft noise were estimated at the place of residence of the participants. No information was available about daytime aircraft noise exposure of the participants when outside their home, especially at their workplace. Misclassification of exposure might occur, especially regarding daytime exposure, because participants were more likely to be outside their home during the day than during the night. However, it is unlikely that the exposure classification would depend on the sleep duration or the feeling of tiredness while awakening. Therefore, such non-differential misclassifications would have induced an appreciable downward bias if there is a true association between aircraft noise exposure and TST or the feeling of tiredness while awakening.

It is worth wondering whether energy-based indicators of exposure such as $\mathrm{L}_{\mathrm{den}}$ or $\mathrm{Lnight}$ were the most relevant indicators to describe the relationship between aircraft noise exposure and sleep duration. Regarding the effects of aircraft noise on sleep quality, it is currently recommended to consider including event-related indicators such as the number of noise events or the number of events exceeding a certain LAmax level (the maximum A-weighted sound pressure level), especially for the night period. In addition to Lden, Lnight and LAeq, 6hr-22hr, it would have been interesting to consider such noise indicators in the present study to increase the impact of these results. Unfortunately, these indicators were not available in France (Evrard, Khati, Champelovier, Lambert, Laumon, 2012). However, in the future, such indicators will be 
available for another study in France on a sub-sample of 110 participants in the DEBATS longitudinal study. For these 110 participants, acoustic measurements at their place of residence were performed for one week.

The fact that TST and the feeling of tiredness while awakening were estimated using a questionnaire could be a limitation in the present study. However, the evaluation of sleep quality with an electroencephalogram (EEG) or with a polysomnography would be very difficult in a large-scale epidemiological study. Nevertheless, the above-cited study on a sub-sample of 110 participants in the longitudinal study will evaluate the objective sleep quality using actimetric measurements. 


\section{Conclusions}

The DEBATS study is the first to investigate the relationship between long-term aircraft noise exposure and sleep duration or the feeling of tiredness while awakening in the morning near French airports. After adjustment for a number of potential confounders (annoyance in particular), an association was observed between short sleep and aircraft noise exposure. The association with the feeling of tiredness while awakening seems to be mediated through annoyance. These findings contribute to the overall evidence suggesting that aircraft noise exposure may decrease the subjective quality of sleep. 


\section{Acknowledgements}

The Airport Pollution Control Authority (Acnusa) requested the French Institute of Science and Technology for Transport, Development and Networks (Ifsttar) for carrying out this study. The authors would like to thank them for their confidence in them.

They are grateful to all the participants in the study.

They also thank Paris Airports and the French Civil Aviation Authority for providing noise exposure maps. They are also grateful to Inès Khati for her participation in the implementation of the study.

\section{Funding}

The present study was supported by funds from the French Ministry of Health, the French Ministry of Environment, and the French Civil Aviation Authority. We would like to thank them for their kind assistance.

\section{Competing interests}

None.

\section{Ethics approval}

The present study was approved by two national authorities in France, the French Advisory Committee for Data Processing in Health Research and the French National Commission for Data Protection and the Liberties. 


\section{References}

Aéroports de Paris. (2007). Exposition au bruit des avions: Aéroport Paris-Charles de Gaulle - Compte rendu annuel 2006. Paris (France), Aéroports de Paris.

Babisch, W., Houthuijs, D., Pershagen, G., Cadum, E., Katsouyanni, K., Velonakis, M., Dudley, M.-L., Marohn, HD., Swart, W., Breugelmans, O., Bluhm, G., Selander, J., Vigna-Taglianti, F., Pisani, S., Haralabidis, A., Dimakopoulou, K., Zachos, \& I., Järup, L.; HYENA Consortium. (2009). Annoyance due to aircraft noise has increased over the years-Results of the HYENA study. Environment International, 35(8), 11691176.

Basner, M., Buess, H., Mueller, U., Plath, G., \& Samel, A. (2004). Aircraft noise effects on sleep: final results of DLR laboratory and field studies of 2240 polysomnographically recorded subject nights (pp. 22-25). Presented at the In 33rd International Congress and Exposition on Noise Control Engineering (Internoise 2004), Prague/Czech Republic.

Basner, M., Glatz, C., Griefahn, B., Penzel, T., \& Samel, A. (2008). Aircraft noise: effects on macro- and microstructure of sleep. Sleep Med, 9(4), 382-7.

Basner, M., Griefahn, B., \& Berg, M. (2010). Aircraft noise effects on sleep: mechanisms, mitigation and research needs. Noise Health, 12(47), 95-109.

Basner, M., \& Samel, A. (2004). Nocturnal aircraft noise effects. Noise Health, 6(22), 83-93.

Beck, F., Richard, J.-B., \& Léger, D. (2013). Prévalence et facteurs sociodémographiques associés à l'insomnie et au temps de sommeil en France (15-85 ans). Revue Neurologique, 169(12), 956-964.

Blois, R., Debilly, G., \& Mouret, J. (1980). Daytime noise and its subsequent sleep effects. Presented at the Proceedings, 3rd International Congress of Noise as a Public Health Problem, Washington, DC: American Speech and Hearing Association. 
Cappuccio, F. P., D’Elia, L., Strazzullo, P., \& Miller, M. A. (2010). Sleep Duration and AllCause Mortality: A Systematic Review and Meta-Analysis of Prospective Studies. Sleep, 33(5), 585-592.

Cappuccio, F. P., Taggart, F. M., Kandala, N., Currie, A., Peile, E., Stranges, S., Miller, M. A., et al. (2008). Meta-analysis of short sleep duration and obesity in children and adults. SLEEP-NEW YORK THEN WESTCHESTER-, 31(5), 619.

Evrard, A.-S., Khati, I., Champelovier, P., Lambert, J., \& Laumon, B. (2012). Health effects of aircraft noise near three French airports: results from a pilot epidemiological study of the DEBATS study. 41st International Congress and Exposition on Noise Control Engineering, INTER-NOISE 2012 (p. 10 p). New-York (USA).

Evrard, A.-S., Lefèvre, M., Champelovier, P., Lambert, J., \& Laumon, B. (2017). Does aircraft noise exposure increase the risk of hypertension in the population living near airports in France? Occupational and Environmental Medicine, 74(2), 123-129.

Finegold, L. S. (2010). Sleep disturbance due to aircraft noise exposure. Noise Health, 12(47), 88-94.

Foret, R., Bruyere, J.-C., \& Yombo, N. 'dogbia. (2005). Etude empirique de la validité du Plan de Gêne Sonore de l'aéroport Lyon-Saint Exupéry (Study report - 12th September 2005). Chambre de commerce et d'industrie de Lyon. Lyon (France).

Frei, P., Mohler, E., \& Roosli, M. (2014). Effect of nocturnal road traffic noise exposure and annoyance on objective and subjective sleep quality. Int J Hyg Environ Health, 217(23), 188-95.

Fruhstorfer, B., Fruhstorfer, H., \& Grass, P. (1984). Daytime noise and subsequent night sleep in man. European Journal of Applied Physiology and Occupational Physiology, 53(2), $159-163$. 
Gangwisch, J. E., Heymsfield, S. B., Boden-Albala, B., Buijs, R. M., Kreier, F., Pickering, T. G., Rundle, A. G., Zammit, G. K., \& Malaspina, D.. (2006). Short Sleep Duration as a Risk Factor for Hypertension: Analyses of the First National Health and Nutrition Examination Survey. Hypertension, 47(5), 833-839.

Gourier-Fréry, C., Chan-Chee, C., \& Léger, D. (2012). Insomnie, fatigue et somnolence: prévalence et état de santé associé, déclarés par les plus de 16 ans en France métropolitaine. Données ESPS 2008. Bull Epidemiol Hebdom, 44, 502-509.

Grandner, M. A., Jackson, N. J., Pak, V. M., \& Gehrman, P. R. (2012). Sleep disturbance is associated with cardiovascular and metabolic disorders: Sleep disturbance and cardiometabolic disorders. Journal of Sleep Research, 21(4), 427-433.

Griefahn, B., Marks, A., \& Robens, S. (2006). Noise emitted from road, rail and air traffic and their effects on sleep. Journal of Sound and Vibration, 295(1-2), 129-140.

He, B., Dinges, E., Hemann, J., Rickel, D., Mirsky, L., Roof, C., Boeker, E. R., Gerbi, P. J. \& Senzig, D. (2007). Integrated Noise Model (INM) Version 7.0 User's Guide. Washington (USA). Federal Aviation Administration.

Jones, K., \& Rhodes, D. P. (2013). Aircraft noise, sleep disturbance and health effects: a review. Stationery Office. London (UK).

Kawada, T., Xin, P., Kuroiwa, M., Sasazawa, Y., Suzuki, S., \& Tamura, Y. (2001). Habituation of Sleep to Road Traffic Noise as Determined by Polysomnography and an Accelerometer. Journal of Sound and Vibration, 242(1), 169-178.

Kim, S. J., Chai, S. K., Lee, K. W., Park, J. B., Min, K. B., Kil, H. G., Lee, C., Lee, C. \& Lee, K.J. (2014). Exposure-Response Relationship Between Aircraft Noise and Sleep Quality: A Community-based Cross-sectional Study. Osong Public Health Res Perspect, 5(2), 108-14. 
Kurina, L. M., McClintock, M. K., Chen, J.-H., Waite, L. J., Thisted, R. A., \& Lauderdale, D. S. (2013). Sleep duration and all-cause mortality: a critical review of measurement and associations. Annals of Epidemiology, 23(6), 361-370.

Kuroiwa, M., Xin, P., Suzuki, S., Sasazawa, Y., Kawada, T., \& Tamura, Y. (2002). Habituation of Sleep to Road Traffic Noise Observed Not by Polygraphy but by Perception. Journal of Sound and Vibration, 250(1), 101-106.

Lefèvre, M., Carlier, M.-C., Champelovier, P., Lambert, J., Laumon, B., \& Evrard, A.-S. (2017). Effects of aircraft noise exposure on saliva cortisol near airports in France. Occupational and Environmental Medicine.

Leger, D., Beck, F., Richard, J. B., Sauvet, F., \& Faraut, B. (2014). The risks of sleeping 'too much’. Survey of a National Representative Sample of 24671 adults (INPES health barometer). PLoS One, 9(9), e106950.

Lekaviciute Gadal, J., Kephalopoulos, S., Stansfeld, S., \& Clark, C. (2013). Final Report of the ENNAH (European Network on Noise and Health) project (EUR - Scientific and Technical Research Reports). Publications Office of the European Union. Luxembourg. Mallon, L., Broman, J.-E., \& Hetta, J. (2000). Relationship Between Insomnia, Depression, and Mortality: A 12-Year Follow-Up of Older Adults in the Community. International Psychogeriatrics, 12(3), 295-306.

Marks, A., \& Griefahn, B. (2007). Associations between noise sensitivity and sleep, subjectively evaluated sleep quality, annoyance, and performance after exposure to nocturnal traffic noise. Noise Health, 9(34), 1-7.

Michaud, D. S., Fidell, S., Pearsons, K., Campbell, K. C., \& Keith, S. E. (2007). Review of field studies of aircraft noise-induced sleep disturbance. J Acoust Soc Am, 121(1), 3241. 
Miedema, H. M., \& Vos, H. (2007). Associations between self-reported sleep disturbance and environmental noise based on reanalyses of pooled data from 24 studies. Behav Sleep Med, 5(1), 1-20.

Muzet, A. (2007). Environmental noise, sleep and health. Sleep Med Rev, 11(2), 135-42.

Ohayon, M. M. (2002). Epidemiology of insomnia: what we know and what we still need to learn. Sleep Medicine Reviews, 6(2), 97-111.

Passchier-Vermeer, W., Vos, H., Steenbekkers, J., van der Ploeg, F., \& Groothuis-Oudshoorn, K. (2002). Sleep disturbance and aircraft noise exposure : Exposure-effect relationships (TNO report No. 2002.027). Division Public Health. Leiden (The Netherlands).

Perron, S., Tetreault, L. F., King, N., Plante, C., \& Smargiassi, A. (2012). Review of the effect of aircraft noise on sleep disturbance in adults. Noise Health, 14(57), 58-67.

Phillips, B., \& Mannino, D. M. (2007). Do insomnia complaints cause hypertension or cardiovascular disease. J Clin Sleep Med, 3(5), 489-494.

Tasali, E., Leproult, R., Ehrmann, D. A., \& Van Cauter, E. (2008). Slow-wave sleep and the risk of type 2 diabetes in humans. Proceedings of the National Academy of Sciences, 105(3), 1044-1049.

Vgontzas, A. N., Liao, D., Pejovic, S., Calhoun, S., Karataraki, M., Basta, M., FernándezMendoza, J. \& Bixler, E.O. (2010). Insomnia with Short Sleep Duration and Mortality: The Penn State Cohort. Sleep, 33(9), 1159-1164.

WHO. (2011). Burden of disease from environmental noise: quantification of healthy life years lost in Europe. Copenhagen: World Health Organization, Regional Office for Europe.

Wood, S. N. (2006). Generalized Additive Models: An Introduction with R. CRC Press. London (UK). 